\title{
No Association between Thrombin Generation and Intra-Plaque Haemorrhage in Symptomatic Carotid Atherosclerotic Plaques: The Plaque at RISK (PARISK) Study
}

Citation for published version (APA):

Crombag, G. A. J. C., Spronk, H. M., Nelemans, P., Schreuder, F. H. B. M., Truijman, M. T. B., van Dijk, A. C., de Rotte, A. A. J., Liem, M. I., Daemen, M. J. A. P., van der Steen, A. F. W., Mess, W. H., Nederkoorn, P. J., Hendrikse, J., van der Lugt, A., Wildberger, J. E., ten Cate, H., van Oostenbrugge, R. J., \& Kooi, M. E. (2018). No Association between Thrombin Generation and Intra-Plaque Haemorrhage in Symptomatic Carotid Atherosclerotic Plaques: The Plaque at RISK (PARISK) Study. Thrombosis and Haemostasis, 118(8), 1461-1469. https://doi.org/10.1055/s-0038-1666858

Document status and date:

Published: 01/08/2018

DOI:

10.1055/s-0038-1666858

Document Version:

Publisher's PDF, also known as Version of record

\section{Document license:}

Taverne

\section{Please check the document version of this publication:}

- A submitted manuscript is the version of the article upon submission and before peer-review. There can be important differences between the submitted version and the official published version of record. People interested in the research are advised to contact the author for the final version of the publication, or visit the DOI to the publisher's website.

- The final author version and the galley proof are versions of the publication after peer review.

- The final published version features the final layout of the paper including the volume, issue and page numbers.

Link to publication

\footnotetext{
General rights rights.

- You may freely distribute the URL identifying the publication in the public portal. please follow below link for the End User Agreement:

www.umlib.nl/taverne-license

Take down policy

If you believe that this document breaches copyright please contact us at:

repository@maastrichtuniversity.nl

providing details and we will investigate your claim.
}

Copyright and moral rights for the publications made accessible in the public portal are retained by the authors and/or other copyright owners and it is a condition of accessing publications that users recognise and abide by the legal requirements associated with these

- Users may download and print one copy of any publication from the public portal for the purpose of private study or research.

- You may not further distribute the material or use it for any profit-making activity or commercial gain

If the publication is distributed under the terms of Article 25fa of the Dutch Copyright Act, indicated by the "Taverne" license above 


\section{No Association between Thrombin Generation and Intra-Plaque Haemorrhage in Symptomatic Carotid Atherosclerotic Plaques: The Plaque at RISK (PARISK) Study}

Geneviève A. J. C. Crombag ${ }^{1,2}$ Henri M. Spronk ${ }^{2,3}$ Patty Nelemans ${ }^{4}$ Floris H. B. M. Schreuder 5,6 Martine T. B. Truijman ${ }^{5,6}$ Anouk C. van Dijk ${ }^{7,8}$ Alexandra A. J. de Rotte ${ }^{9}$ Madieke I. Liem $^{10}$ Mat J. A. P. Daemen ${ }^{11}$ Anton F. W. van der Steen ${ }^{12}$ Werner H. Mess ${ }^{2,6}$ Paul J. Nederkoorn ${ }^{10}$ Jeroen Hendrikse ${ }^{9}$ Aad van der Lugt $^{7}$ Joachim E. Wildberger ${ }^{1,2}$ Hugo ten Cate ${ }^{2,3}$ Robert J. van Oostenbrugge ${ }^{2,4}$ M. Eline Kooi ${ }^{1,2}$

${ }^{1}$ Department of Radiology and Nuclear Medicine, Maastricht University Medical Centre, Maastricht University, Maastricht, The Netherlands

${ }^{2}$ CARIM School for Cardiovascular Diseases, Maastricht University Medical Centre, Maastricht University, Maastricht, The Netherlands

${ }^{3}$ Department of Internal Medicine, Clinical Thrombosis and Haemostasis Laboratory, Maastricht University Medical Centre, Maastricht University, Maastricht, The Netherlands

4 Department of Epidemiology, Maastricht University Medical Centre, Maastricht University, Maastricht, The Netherlands

${ }^{5}$ Department of Neurology, Maastricht University Medical Centre, Maastricht University, Maastricht, The Netherlands

${ }^{6}$ Department of Clinical Neurophysiology, Maastricht University Medical Centre, Maastricht University, Maastricht, The Netherlands

${ }^{7}$ Department of Radiology, Erasmus Medical Centre, Erasmus

University, Rotterdam, The Netherlands
Address for correspondence M. Eline Kooi, PhD, P. Debyelaan 25, Post box 5800, 6202 AZ Maastricht, The Netherlands

(e-mail: eline.kooi@mumc.nl).

${ }^{8}$ Department of Neurology, Erasmus Medical Centre, Erasmus University, Rotterdam, The Netherlands

${ }^{9}$ Department of Radiology, University Medical Centre Utrecht, Utrecht University, Utrecht, The Netherlands

${ }^{10}$ Department of Neurology, Academic Medical Centre, University of Amsterdam, Amsterdam, The Netherlands

${ }^{11}$ Department of Pathology, Academic Medical Centre, University of Amsterdam, Amsterdam, The Netherlands

${ }^{12}$ Department of Biomedical Engineering, Erasmus Medical Centre, Erasmus University, Rotterdam, The Netherlands

Thromb Haemost 2018;118:1461-1469.
Abstract
Keywords
- carotid stenosis
- ischaemic attack
- transient
- magnetic resonance imaging
- stroke
- thrombin

Background Carotid atherosclerosis is an important cause of stroke. Intra-plaque haemorrhage (IPH) on magnetic resonance imaging (MRI) increases stroke risk. Development of IPH is only partly understood. Thrombin is an essential enzyme in haemostasis. Experimental animal studies have shown conflicting results on the relation between thrombin and plaque vulnerability. We hypothesize that decreased thrombin generation (TG) is associated with IPH and plaque vulnerability.

Objective This article investigates whether TG is associated with IPH and other features of plaque vulnerability in stroke patients.

Methods Recently symptomatic stroke patients underwent carotid MRI and blood sampling. MRI plaque features include plaque burden, presence of IPH, amount of lipidrich necrotic core (LRNC), calcified tissue and fibrous tissue (\% of total wall volume). TG was assessed in platelet-poor plasma and expressed as: peak height (PH) and endogenous thrombin potential (ETP). MR images could be analysed in 224 patients. Blood samples were available in 161 of 224 patients. Binary multivariate logistic and linear regression were used to investigate the association between TG and MRI plaque features. received

November 3, 2017

accepted after revision

May 20, 2018
(C) 2018 Georg Thieme Verlag KG Stuttgart . New York
DOI https://doi.org/ 10.1055/s-0038-1666858. ISSN 0340-6245. 
Results IPH and LRNC were present in 65 (40\%) and 102 (63\%) of plaques. There were no significant associations between TG and IPH; PH odds ratio $(\mathrm{OR})=1$, 95\% confidence interval (Cl): 0.76 to 1.45 and $\mathrm{ETPOR}=1,95 \% \mathrm{Cl}: 0.73$ to 1.37 . After correction for age, sex and hypercholesterolaemia, the association was weak but non-significant; $\mathrm{PH}: \mathrm{OR}=0.76$, 95\% Cl: 0.52 to 1.10 and ETP: OR $=0.73,95 \% \mathrm{Cl}: 0.53$ to 1.37 .

Conclusion Features of carotid plaque on MRI show no significant association with TG in stroke patients. Systemic TG does not seem to be an important factor in IPH development.

\section{Introduction}

Atherosclerosis of the carotid artery is an important cause of ischaemic stroke. ${ }^{1}$ The degree of luminal narrowing and the presence of symptoms are currently leading in the treatment decisions in patients with carotid artery disease. ${ }^{2}$ Numerous histopathological studies have shown that rupture of a vulnerable atherosclerotic plaque is the main underlying cause of stroke in patients with carotid artery disease. ${ }^{3}$ Magnetic resonance imaging (MRI) allows non-invasive semi-quantitative visualization of the hallmarks of plaque vulnerability including intra-plaque haemorrhage (IPH), lipid-rich necrotic core (LRNC) and a thin or ruptured fibrous cap (FC). ${ }^{4-8}$

An important feature of plaque vulnerability is $\mathrm{IPH}^{8-10}$ Meta-analyses have demonstrated that IPH in carotid atherosclerotic plaques on MRI is a strong predictor for ischaemic stroke. ${ }^{11-14}$ Plaques with IPH also show accelerated plaque progression. ${ }^{10}$

The development of IPH is only partly understood. Several factors, or a combination of these factors, could contribute to the development of IPH. First, neo-vessels growing from vasa vasorum in the adventitia into the plaque are known to be immature and are highly susceptible to leakage of erythrocytes into the plaque, which may result in IPH. ${ }^{15}$ Second, on the luminal side, plaque rupture and subsequent healing may play a role in the development of IPH. ${ }^{16-18}$ At the site of plaque disruption or ulceration, the coagulation system will be activated and a luminal thrombus will be formed. During healing, the erythrocyte-rich thrombus can be incorporated into the vessel wall. ${ }^{18,19}$ Additionally, fissures in the FC may contribute to IPH. ${ }^{17,20}$ Fissures, defined as minor luminal surface disruptions that otherwise do not alter the overall luminal shape, are very common in advanced carotid plaques and are frequently connected to IPH. ${ }^{21}$ Last, impaired coagulation could play a role in the development of IPH, since IPH is associated with anti-platelet therapy and vitamin $\mathrm{K}$ antagonists (VKAs). ${ }^{22,23}$

Thrombin is a central protease in the coagulation cascade. Its most important function is the conversion of fibrinogen into fibrin, a key step in clot formation. ${ }^{24}$ Other pleiotropic actions of thrombin are inducing pro-inflammatory mediators as well as oxidative stress and mediating the migration and proliferation of vascular smooth muscle cells (VSMCs). ${ }^{25}$ Thrombin generation is dependent on almost all coagulation factors and can be associated with a bleeding tendency, that is, less production of thrombin, as well as hypercoagulability, that is, increased thrombin generation. ${ }^{26}$
Recent animal studies have shown conflicting results on the relation between thrombin generation and atherosclerotic plaque vulnerability. Direct thrombin inhibition showed an inhibitory effect on atherosclerosis, most likely via lowering vascular oxidative stress and reducing macrophage infiltration. ${ }^{27-29}$ In line, apolipoprotein E-deficient mice treated with a thrombin inhibitor showed a thicker FC and decreased plaque lipid content. ${ }^{30}$ A recent study showed that hypercoagulability promotes more severe atherosclerosis, including large necrotic cores, signs of IPH, thin FCs and increased thrombin generation. After administration of a thrombin inhibitor, this mouse model showed less extensive atherosclerosis of a more stable plaque phenotype. ${ }^{31}$ In sharp contrast, another study suggested that thrombin has a stabilizing effect on atherosclerotic plaques via decreased monocyte transmigration. The plaques from the mice models carrying a pro-thrombotic mutation, showed larger plaques but with a more stable phenotype (less necrotic cores, more smooth muscle cells and fewer macrophages). ${ }^{32}$

While experimental studies provide support for the idea that increased thrombin production in blood alters the plaque phenotype, while genetic or pharmacological inhibition of coagulation attenuates atherogenesis, human data are scarce. Human data on the relation between thrombin generation and stroke show conflicting results. Carcaillon et $\mathrm{al}^{33}$ described a positive association between high levels of thrombin generation and an increased risk of acute ischaemic stroke, while Loeffen et $\mathrm{al}^{34}$ showed that decreased thrombin generation is an independent predictor for stroke. The abundant presence of coagulation proteins in the human atherosclerotic vessel wall ${ }^{35}$ suggests that local variation in thrombin formation may have an impact on diverse cellular processes within the plaque. In conjunction, these findings led us to hypothesize that increased thrombin generation would affect the human plaque phenotype, towards reduced plaque vulnerability. Therefore, the present explorative, cross-sectional study aims to investigate whether there is an association between the morphological plaque features (i.e. presence of IPH and plaque burden, percentages of LRNC, calcified tissue and fibrous tissue) as assessed by carotid MRI and thrombin generation parameters.

\section{Materials and Methods}

\section{Study Population}

Baseline data from stroke patients included in the Plaque at Risk (PARISK) study were used (clinical trials.gov NCT01208025). ${ }^{36}$ Patients were enrolled in the PARISK study from September 2010 
until November 2014. Consecutive patients who had recent ( $<3$ months) neurological symptoms due to ischaemia, and an ipsilateral carotid atherosclerotic plaque with a stenosis of $<70 \%$ according to the North American Symptomatic Carotid Endarterectomy Trial (NASCET) criteria were eligible for inclusion. The lower cut-off value is an atherosclerotic plaque with a thickness of at least 2 to $3 \mathrm{~mm}$, which corresponds to an European Carotid Surgery Trial (ECST) stenosis of 30\%. ${ }^{37}$ Exclusion criteria were clotting disorders, a probable cardiac source of embolism, standard contraindications for MRI, severe comorbidity or a carotid revascularization procedure. If the renal clearance was below $<30 \mathrm{~mL} / \mathrm{min}$, no contrast medium was injected. Institutional medical committee approval was obtained and all patients provided written informed consent.

\section{MR Imaging Data Acquisition and Analysis}

Patients underwent an MRI examination on a 3T system (Achieva; Philips Healthcare, Best, the Netherlands; or Discovery MR 750; GE Healthcare, Milwaukee, Wisconsin, United States) using a dedicated phased-array carotid radiofrequency coil (Shanghai Chenguang Medical Technologies Co, Shanghai, China; or Machnet B.V., Roden, The Netherlands). A multisequence MRI protocol, as described previously, ${ }^{36}$ was used to obtain 15 transverse adjoining slices of $2 \mathrm{~mm}$ each covering the entire plaque. Dedicated vessel wall imaging analysis software (VesselMass, Department of Radiology, Leiden University Medical Centre, The Netherlands) was used to delineate plaque components. The presence of IPH was scored on T1-weighted (T1W) inversion recovery transient field echo or spoiled gradient echo MR images within the symptomatic carotid plaque by trained observers ( - Fig. 1). IPH was considered present in case of a hyper-intense signal in the bulk of the plaque, compared with the sternocleidomastoid muscle. A LRNC was identified as a region within the bulk of the plaque that did not show contrast enhancement on the post-contrast T1W double or quadruple inversion recovery images. Calcifications were defined as areas with hypo-intense signal relative to the signal of the adjacent sternocleidomastoid muscle in at least two different MRI weightings. The fibrous content of the atherosclerotic plaques was calculated as the difference between the total wall volume and the volume of the LRNC and calcifications together.

\section{Thrombin Generation}

Citrated platelet-poor plasma (PPP) samples were derived from the blood samples taken at baseline. The thrombin generation test analyses the amount of thrombin being formed in time in a certain amount of plasma after coagulation activation. Venous blood was collected in $3.2 \%$ citrate (Greiner Bio-One) and PPP was prepared by two centrifugation steps: the first at $2,500 \times g$ for 5 minutes and the second at $15,280 \times g$ for 10 minutes. Plasma aliquots were snapfrozen in liquid nitrogen, stored at $-80^{\circ} \mathrm{C}$ until use. All samples were thawed at $37^{\circ} \mathrm{C}$ for 15 minutes before analysis and analysed batch wise. The assay was performed using the validated calibrated automated thrombogram (CAT, Thrombinoscope BV, Maastricht, The Netherlands). Tissue factor (TF) ( $1 \mathrm{PM} \mathrm{TF} \pm$ thrombomodulin [TM]) and phospholipids are added to $80 \mu \mathrm{L}$ PPP. As described previously, the concentration of in-house recombinant expressed and purified soluble TM was chosen such as to inhibit thrombin generation in normal pooled plasma by $50 \%{ }^{38}$ Parallel, $20 \mu \mathrm{L}$ calibrator is added to another sample of the same $80 \mu \mathrm{L}$
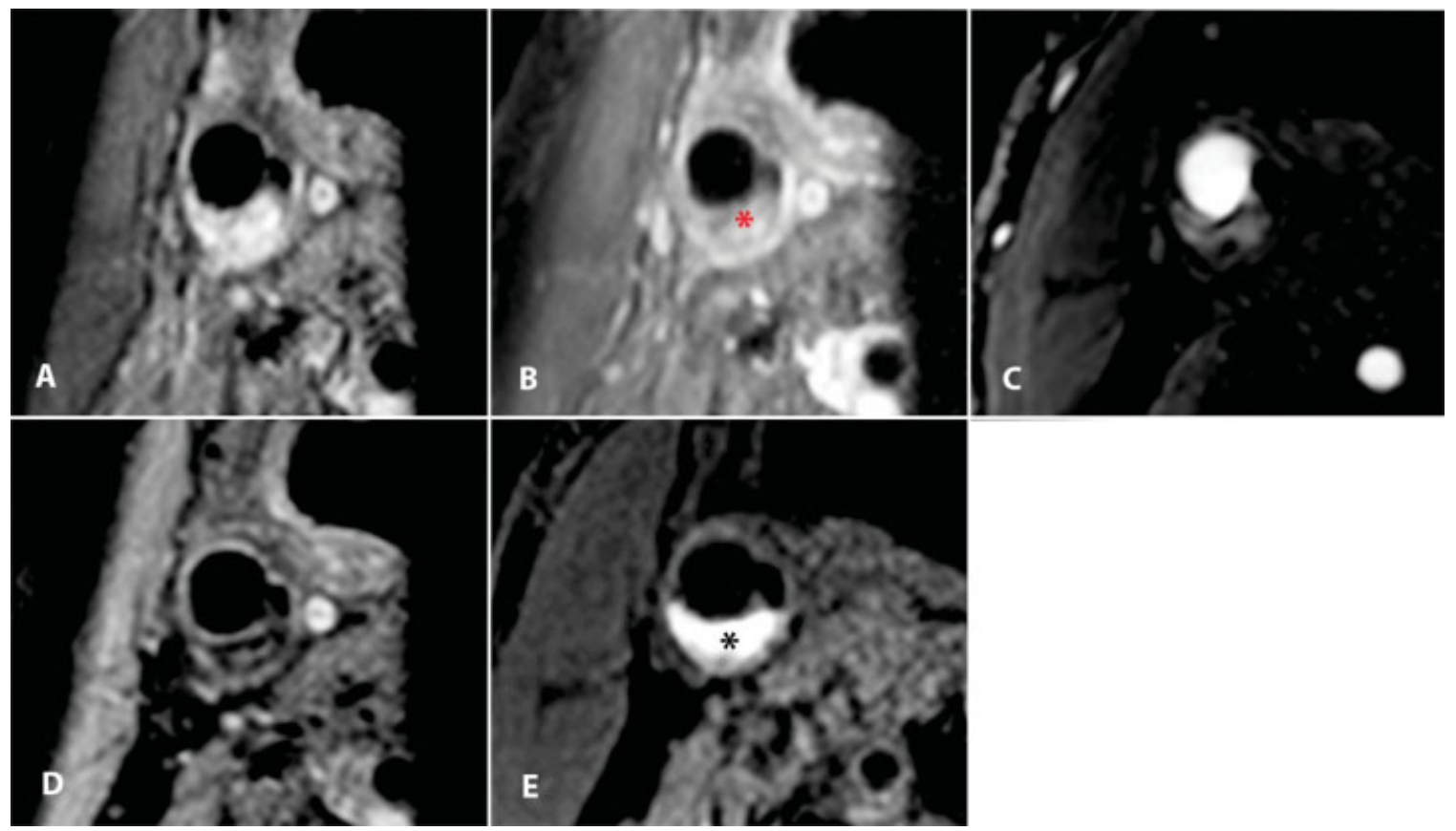

Fig. 1 Transversal magnetic resonance (MR) images of a carotid plaque in the right carotid artery. The following MR sequences were acquired (A) pre-contrast T1-weighted (T1W) quadruple inversion recovery (QIR) turbo spin echo (TSE), (B) post-contrast T1W QIR TSE, (C) time of flight (TOF), (D) T2W TSE and (E) T1W inversion recovery (IR) turbo field echo (TFE). A lipid-rich necrotic core was identified as a region within the bulk of the plaque that does not show contrast enhancement ( ${ }^{*}$ on B) on the post-contrast T1W QIR images. On the T1 IR-TFE image, a hyper-intense signal in the bulk of the plaque can be clearly observed, indicating the presence of intra-plaque haemorrhage $\left({ }^{*}\right.$ on panel E). 
PPP. Addition of a fluorescent substrate (ZGGR-AMC) and calcium ions is used to set off the thrombin generation. The conversion of the fluorescent substrate into a fluorophore product is continuously registered using a Fluoroskan Ascent reader (Thermo Labsystems OY, Helsinki, Finland) equipped with a 390/460 filter set. Thrombin generation curves were calculated using the Thrombinoscope software (Thrombinoscope BV). From the thrombogram or thrombin generation curve, the area under the curve and the peak height were derived. The first parameter (area under the curve) reflects the potential of active thrombin, also called the endogenous thrombin potential (ETP). The second parameter (peak height) represents the maximum thrombin generation (-Fig. 2).

\section{Statistical Analysis}

All calculations were made with SPSS version 23 (IBM Corporation, Armonk, New York, United States). A p-value of $<0.05$ was considered statistically significant. A chisquare test was used to compare categorical variables between groups with and without IPH. A t-test for independent samples was used to compare continuous variables between these groups. The distribution of continuous MRI parameters was tested for normality before and after logarithmic transformation. Linear regression analysis was used if the dependent (log transformed) continuous MRI parameters had a normal distribution. If logarithmic transformation did not result in a normal distribution, binary logistic regression was performed using the median value of MRI

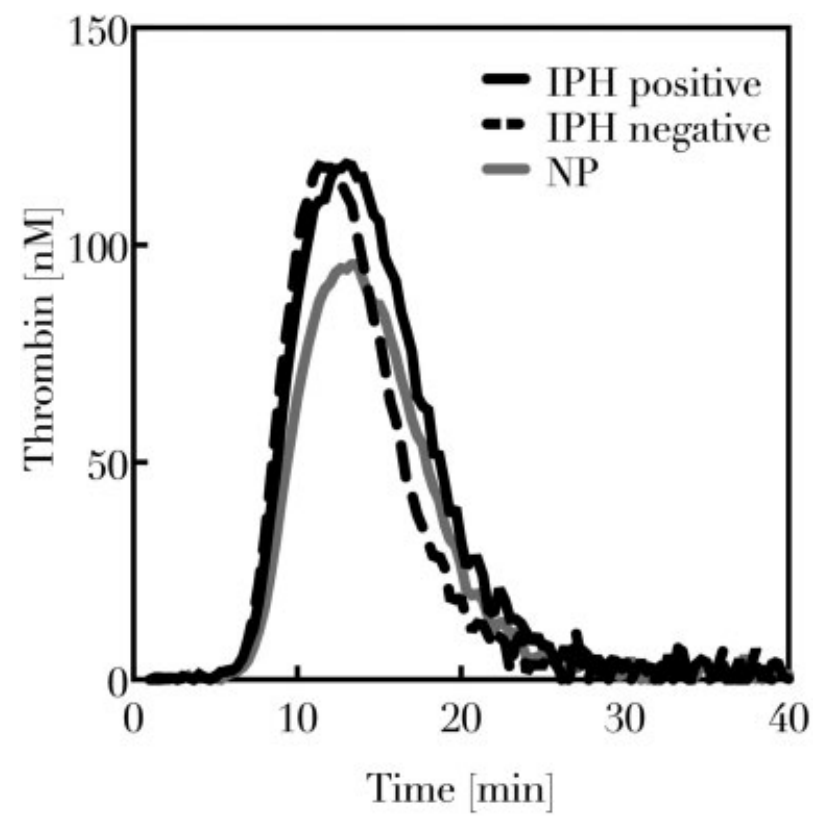

Fig. 2 Example of a thrombin generation curve in citrated plateletpoor plasma generated using the calibrated automated thrombogram (CAT) method. The two derived parameters are the maximum thrombin generation (peak height) and the endogenous thrombin potential (ETP) (area under the curve). The data shown are from a subject with intra-plaque haemorrhage (black line), a subject without intra-plaque haemorrhage (interrupted line) as well as the normal plasma (grey line). parameters as a cut-off value for dichotomization of the relevant MRI parameters.

The association between thrombin generation parameters and dependent MRI parameters is expressed as the regression coefficient per standard deviation increase in thrombin generation parameter (in case of linear regression) or the odds ratio (exponentiated regression coefficient) per standard deviation increase in thrombin generation parameter (in case of logistic regression). Both 95\% confidence intervals and $p$-values were calculated. The use of one standard deviation as unit facilitates more meaningful interpretation and comparison of the associations with peak thrombin and ETP, which are continuous variables with different scales.

Multivariate logistic regression models were performed to adjust for between-group differences in relevant clinical variables (age, sex and hypercholesterolaemia) which were significantly associated with IPH risk in univariate analyses $(p<0.05)$.

\section{Results}

Carotid MRI data were available in 229 out of the 244 included patients (exclusion due to: withdrawn informed consent $[n=6]$, no MRI carotids due to claustrophobia $[n=6]$, obesity $[n=2]$ or unknown reason $[n=1])$. Another 5 patients were excluded from the analysis due to poor quality of the MRI of the carotid artery $(n=4)$ or due to an incomplete MRI protocol $(n=1)$. A plasma sample was available for thrombin generation analysis in 164 out of the remaining 224 patients. Another 3 patients were excluded from the analysis because of anti-coagulant use prior to the event (acenocoumarol, $n=3$ ). Thus, final analysis was performed in 161 patients.

The distribution of clinical characteristics, thrombin generation levels and imaging characteristics for the total study population and for patients with and without IPH are shown in - Table 1. IPH was detected in the ipsilateral carotid plaque in 65 out of 161 patients (40.4\%). A LRNC was detected in 102 of 161 (63.4\%) patients. Patients with IPH were relatively older, more often male and had more frequently hypercholesterolaemia.

- Table 1 shows that there were no significant differences in peak thrombin and ETP values between subjects with and without IPH ( $p=0.868$ and $p=0.938$, respectively). However, significant differences in age, sex and hypercholesterolaemia between patients with and without IPH necessitated multivariate regression analyses.

- Table 2 shows the results from uni- and multivariate logistic regression analyses. The odds ratios represent the association with different MRI parameters for one standard deviation increase in the thrombin generation parameters. Peak thrombin and ETP differ in range and the use of one standard deviation as unit was done to facilitate more meaningful interpretation and comparison of the odds ratios for peak thrombin and ETP. Crude odds ratios for IPH (not adjusted for sex, age and hypercholesterolaemia) are 1, suggesting absence of an association between thrombin generation parameters and risk of IPH. 
Table 1 Clinical characteristics

\begin{tabular}{|c|c|c|c|c|}
\hline Clinical characteristics $(n=161)$ & Total $(n=161)$ & $\mathrm{IPH}(n=65)$ & No IPH $(n=96)$ & $p$-Value \\
\hline Age $(y)$, mean $\pm S D$ & $68.9( \pm 8.7)$ & $70.6( \pm 9.07)$ & $67.7( \pm 9.07)$ & 0.032 \\
\hline Male & $117(73 \%)$ & $58(89 \%)$ & $59(62 \%)$ & $<0.001$ \\
\hline Current smoking & $33(21 \%)$ & $9(14 \%)$ & $24(25 \%)$ & 0.113 \\
\hline $\mathrm{BMI}$, mean $\pm \mathrm{SD}$ & $26( \pm 4)$ & $27(4)$ & $27(4)$ & 0.727 \\
\hline Hypertension & $103(64 \%)$ & $46(71 \%)$ & $57(59 \%)$ & 0.124 \\
\hline Hypercholesterolaemia & $91(57 \%)$ & $43(66 \%)$ & $48(50 \%)$ & 0.040 \\
\hline Diabetes mellitus & $35(22 \%)$ & $15(23 \%)$ & $20(21 \%)$ & 0.722 \\
\hline History of CVD and PAD & $30(19 \%)$ & $39(60 \%)$ & $51(53 \%)$ & 0.668 \\
\hline \multicolumn{5}{|l|}{ Classification of event } \\
\hline TIA & $68(42 \%)$ & $21(32 \%)$ & $47(49 \%)$ & \multirow[t]{3}{*}{0.108} \\
\hline Stroke & $71(44 \%)$ & $34(52 \%)$ & $37(39 \%)$ & \\
\hline Amaurosis fugax & $22(14 \%)$ & $10(15 \%)$ & $12(13 \%)$ & \\
\hline \multicolumn{5}{|l|}{ Medication prior to event } \\
\hline Anti-platelets & $68(42.2 \%)$ & $33(51 \%)$ & $35(37 \%)$ & 0.080 \\
\hline Anti-coagulants & - & - & - & - \\
\hline Statins & $76(47 \%)$ & $31(48 \%)$ & $45(47 \%)$ & 0.467 \\
\hline Anti-hypertensives & $96(60 \%)$ & $43(66 \%)$ & $53(55 \%)$ & 0.165 \\
\hline \multicolumn{5}{|l|}{ Blood measurements $(n=161)$, mean \pm SD } \\
\hline Interval event-blood withdrawal (d) & $48( \pm 22)$ & $50( \pm 23)$ & $46( \pm 21)$ & 0.326 \\
\hline Peak thrombin (nM), range (69.81-508.42) & $223.45( \pm 93.46)$ & $224.95( \pm 89.90)$ & $222.44( \pm 96.25)$ & 0.868 \\
\hline ETP (nM/min), range (606.10-2208.99) & $1344.93( \pm 314.50)$ & $1342.56( \pm 308.19)$ & $1346.53( \pm 320.30)$ & 0.938 \\
\hline \multicolumn{5}{|l|}{$\mathrm{MRI}$} \\
\hline Interval event-MRI (d), mean \pm SD & $49( \pm 21)$ & $50( \pm 22)$ & $47( \pm 21)$ & 0.332 \\
\hline Normalized wall index (NWI), mean \pm SD & $0.2398( \pm 0.23)$ & $0.33( \pm 0.21)$ & $0.18( \pm 0.23)$ & 0.424 \\
\hline $\begin{array}{l}\text { \% Lipid-rich necrotic core tissue, } \\
\text { median (range) }\end{array}$ & $2.3(0-43.9)$ & $13.31(0-43.9)$ & $0.00(0-18.0)$ & $<0.001$ \\
\hline \% Calcified tissue, median (range) & $3.7(0-22.4)$ & $3.4(0-22.4)$ & $3.7(0-21.7)$ & 0.847 \\
\hline \% Fibrous tissue, median (range) & $91.6(50.3-100)$ & $80.8(50.3-98.4)$ & $94.7(74.88-100)$ & $<0.001$ \\
\hline Thin/ruptured fibrous cap ${ }^{a}$ & $63(39 \%)$ & $49(75 \%)$ & $14(15 \%)$ & $<0.001$ \\
\hline
\end{tabular}

Abbreviations: BMI, body mass index; CVD, cardiovascular disease; ETP, endogenous thrombin potential; IPH, intra-plaque haemorrhage; MRI, magnetic resonance imaging; PAD, peripheral artery disease; SD, standard deviation; TIA, transient ischaemic attack. Note: Clinical characteristics, data are presented as mean \pm standard deviation or absolute numbers of patients (\%).

${ }^{a}$ Data available for 157 out of 161 patients ( 4 patients had no post-contrast sequence available to analyse the fibrous cap status).

-Table 2 also shows odds ratios per standard deviation increase in thrombin generation parameters for high versus low percentages of LRNC, calcified tissue and fibrous tissue. Crude odds ratios (not adjusted for sex, age and hypercholesterolaemia) near 1 suggest absence of an association with high percentage of lipid, calcified or fibrous tissue. However, after adjustment for potential confounders weak positive associations were observed; however, these were non-significant. The confounding effect could not be appointed to sex alone, because also age and hypercholesterolaemia showed a confounding effect on these three MRI parameters. ${ }^{39}$

- Table 3 shows odds ratios per unit increase in normalized wall index (NWI, plaque burden). Since NWI was a continuous MRI parameter with a normal distribution, we used a linear regression to investigate associations with thrombin generation parameters. The regression coefficient is therefore per unit increase of peak thrombin and ETP. No association was found between thrombin generation parameters and NWI.

There was no significant association between thrombin generation and IPH if we additionally corrected for LRNC, fibrous tissue and FC status (data not shown). There was also no significant association between thrombin generation and MRI parameters when TM was added (data not shown).

\section{Discussion}

This study shows no significant association between thrombin generation parameters in blood plasma and features of 
Table 2 Results of the univariate and multivariate binary logistic regression analysis to study the association between thrombin generation parameters and the presence of intra-plaque haemorrhage (IPH) and other MRI parameters: high versus low percentages of lipid-rich necrotic core (LRNC), calcified tissue and fibrous tissue

\begin{tabular}{|c|c|c|c|c|c|c|c|}
\hline & & \multicolumn{3}{|c|}{ Univariate analysis } & \multicolumn{3}{|c|}{ Multivariate analysis $^{a}$} \\
\hline & & $\begin{array}{l}\text { OR } \\
\text { (per SD } \\
\text { increase) }\end{array}$ & $95 \% \mathrm{Cl}$ & $p$-Value & $\begin{array}{l}\text { OR } \\
\text { (per SD } \\
\text { increase) }\end{array}$ & $95 \% \mathrm{Cl}$ & $p$-Value \\
\hline \multirow[t]{2}{*}{ IPH presence } & Peak thrombin & 1 & $0.76-1.45$ & 0.867 & 0.76 & $0.52-1.10$ & 0.200 \\
\hline & ETP & 1 & $0.73-1.37$ & 0.937 & 0.73 & $0.53-1.37$ & 0.122 \\
\hline \multirow{2}{*}{$\begin{array}{l}\text { \% LRNC } \\
(\geq 2.33 \text { vs. }<2.33)\end{array}$} & Peak thrombin & 1.20 & $0.76-1.45$ & 0.697 & 0.83 & $0.57-1.20$ & 0.348 \\
\hline & ETP & 1 & $0.73-1.37$ & 0.883 & 1 & $0.53-1.37$ & 0.089 \\
\hline \multirow{2}{*}{$\begin{array}{l}\text { \% Calcified tissue } \\
(\geq 3.73 \text { vs. }<3.73)\end{array}$} & Peak thrombin & 1.20 & $0.83-1.59$ & 0.339 & 1.20 & $0.53-1.74$ & 0.292 \\
\hline & ETP & 1 & $0.73-1.37$ & 0.398 & 1.37 & $1.00-1.87$ & 0.144 \\
\hline \multirow{2}{*}{$\begin{array}{l}\text { \% Fibrous tissue } \\
(\geq 91.58 \text { vs. }<91.58)\end{array}$} & Peak thrombin & 1 & $0.76-1.45$ & 0.796 & 1.32 & $0.91-1.74$ & 0.186 \\
\hline & ETP & 1 & $0.73-1.37$ & 0.535 & 1.37 & $1.00-1.87$ & 0.087 \\
\hline \multirow[t]{2}{*}{ Fibrous cap status } & Peak thrombin & 1 & $0.76-1.45$ & 0.789 & 0.76 & $0.52-1.10$ & 0.192 \\
\hline & ETP & 1 & $0.73-1.37$ & 0.674 & 0.73 & $0.53-1.37$ & 0.090 \\
\hline
\end{tabular}

Abbreviations: $\mathrm{Cl}$, confidence interval; ETP, endogenous thrombin potential; IPH, intra-plaque haemorrhage; LRNC, lipid-rich necrotic core; MRI, magnetic resonance imaging; OR, odds ratio.

Note: The odds ratios represent the change in the odds of an event for increase by one standard deviation (SD) in peak thrombin (SD $=93 \mathrm{nM}$ ) and one standard deviation in ETP (SD = $314 \mathrm{nM} / \mathrm{min})$ with 95 percentage confidence interval.

${ }^{a}$ Corrected for age, sex and hypercholesterolaemia.

Table 3 Results of the univariate and multivariate linear regression analysis to study the association between thrombin generation parameters and the normalized wall index (NWI, plaque burden)

\begin{tabular}{|c|l|l|l|l|l|l|l|}
\hline \multicolumn{2}{|c|}{} & \multicolumn{2}{|l|}{ Univariate analysis } & \multicolumn{2}{l|}{ Multivariate analysis ${ }^{\text {a }}$} \\
\cline { 3 - 8 } & $\begin{array}{l}\text { Regression } \\
\text { coefficient } \\
\text { (per unit increase) }\end{array}$ & $95 \% \mathrm{Cl}$ & $p$-Value & $\begin{array}{l}\text { Regression } \\
\text { coefficient } \\
\text { (per unit increase) }\end{array}$ & 95\% Cl & $p$-Value \\
\hline \multirow{2}{*}{$\mathrm{NWI}$} & $\begin{array}{l}\text { Peak } \\
\text { thrombin }\end{array}$ & -0.001 & -0.001 to 0.000 & 0.940 & 0.000 & -0.001 to 0.000 & 0.255 \\
\cline { 2 - 8 } & ETP & -0.001 & -0.001 to 0.000 & 0.614 & -0.001 & -0.001 to 0.000 & 0.135 \\
\hline
\end{tabular}

Abbreviations: $\mathrm{Cl}$, confidence interval; ETP, endogenous thrombin potential; NWI, normalized wall index.

${ }^{a}$ Corrected for age, sex and hypercholesterolaemia.

carotid plaque on MRI, including IPH, in symptomatic patients with a mild to moderate ipsilateral carotid artery stenosis.

There is clear evidence in the literature that IPH is a key aspect of plaque vulnerability contributing to clinical events. However, the development of IPH is only partly understood. Impaired thrombin generation may promote IPH development, since Borissoff et al demonstrated signs of IPH in hyper-coagulable mice carrying a TM gene mutation resulting in diminished TM-dependent generation of activated protein $\mathrm{C}^{31}$ On the other hand, we and others demonstrated an increased frequency of IPH in patients on coumarin-type anti-coagulants ${ }^{23,40}$ and anti-platelet therapy. 22,41,42

In this study, we explored a possible role of the plasmatic coagulation cascade to IPH development by quantification of thrombin generation. The present results do not show a significant association between systemic coagulation factors and IPH. The odds ratios for the presence of IPH showed a negative weak association with thrombin generation in this study, indicating that an increase in thrombin generation may protect against IPH in accordance with our hypothesis; however, the association lacked statistical significance. Our sample size may have been too small to reach statistical significance or alternatively this may have been a coincidental finding. On the other hand, a positive non-significant weak association was found for the other MRI plaque features with thrombin generation. This is in line with a previous study, which found a positive association between thrombin generation and plaques with a higher content of fibrous and calcified tissue in 128 patients with a $\geq 35 \%$ lumen diameter reduction. ${ }^{43}$

The estimation of thrombosis risk using a CAT has been validated in previous research. The assay allows for broad 
scale clinical testing, although it is not yet implemented in daily clinical practice. ${ }^{44-47}$ Associations between thrombin generation and atherothrombotic events have been studied previously. A positive association was shown with ischaemic stroke, $^{33}$ echogenic carotid plaques ${ }^{43}$ and intima-media thickness. ${ }^{48}$ Besides, histopathological evidence shows a pro-coagulant state in early atherosclerotic lesions. ${ }^{35}$ However, the association between thrombin parameters and morphological atherosclerotic features on carotid MRI has not been studied before.

Li et al observed a positive association between the use of coumarins and the presence and extent of IPH in coronary plaques. ${ }^{23}$ VKAs reduce the level of different pro- and anticoagulant proteins, resulting in diminished thrombin generation in plasma. ${ }^{49}$ An important difference between anticoagulant-mediated effects and variations in endogenous plasma thrombin generation may be in the local, intravascular inhibitory effects that may be operational with oral anti-coagulants. Atherosclerotic lesions express a range of coagulation proteins, including factor VII that is also synthesized by VSMCs. ${ }^{35}$ Theoretically, VKA may also inhibit the function of such extra-vascular proteins, which might contribute to less thrombin generation potential in the plaque. Consequently, this may reduce pro-coagulant and pro-fibrotic actions of thrombin and may promote IPH and plaque vulnerability. This additional, local effect, may be required to contribute to IPH, whereas variations in systemic thrombin generation do not have such impact on plaque stability. Animal experimental work with novel oral anticoagulants also shows strong effects on plaque progression and features of stability. ${ }^{27,28,30}$

Previously, Liem et al has shown an association between IPH and anti-platelet therapy. ${ }^{22}$ To eliminate the contribution of platelets and to focus on the contribution of plasma factors only, we used PPP in our study. Nevertheless, thrombin generation analysis in platelet-rich plasma might be interesting in future studies, but requires a new study setup as fresh material is needed for such an assay.

In addition, the patients in the PARISK study are not scheduled for carotid endarterectomy, so we were unable to study the effects of local thrombin concentrations within the atherosclerotic lesion. Previous studies in the literature have suggested that local coagulation factors may play a crucial role in atherothrombosis and atherosclerotic plaque progression..$^{25,35}$ We could not study the relation between IPH and thrombin and clinical events during follow-up, since the clinical follow-up of the PARISK study is still on-going. However, the main goal of this study was to identify an association between thrombin generation and plaque composition in patients with a recently symptomatic carotid atherosclerotic plaque. This study was not designed to investigate the relation between thrombin and atherosclerotic plaque development.

\section{Conclusion}

Features of carotid plaque on MRI show no significant association with thrombin generation in stroke patients.
Systemic thrombin generation does not seem to be an important factor in IPH development.

\section{What is known about this topic?}

- Intra-plaque haemorrhage (IPH) is an important hallmark of carotid plaque vulnerability.

- Experimental animal studies have shown conflicting results on the relation between thrombin and atherosclerotic plaque vulnerability.

- Recent experimental studies provide support for the idea that increased thrombin production in blood alters the plaque phenotype, while genetic or pharmacological inhibition of coagulation attenuates atherogenesis, human data are scarce

\section{What does this paper add?}

- We demonstrated no associations between thrombin generation and magnetic resonance imaging parameters.

- Systemic thrombin generation does not seem to be an important factor in IPH development.

Note

ClinicalTrials.gov Identifier, NCT Number: NCT01208025.

Funding

This research was performed within the framework of CTMM, project PARISk (grant 01C-202), and supported by the Dutch Heart Foundation. This project has received funding from the European Union (EU) Horizon 2020 research and innovation program under the Marie Skłodowska-Curie grant agreement No 722609.

Conflict of Interest

Prof. Dr. H. ten Cate is a consultant to Stago. Prof. Dr. J.E. Wildberger and Prof. Dr. M.E. Kooi are supported by Stichting de Weijerhorst. Prof. Dr. J.E. Wildberger receives institutional grants from AGFA, Bayer, GE, Philips, Siemens and is in the speaker's bureau for Bayer and Siemens (all outside the submitted work).

\section{Acknowledgements}

Participating centres: Academic Medical Center, Amsterdam (P.J. Nederkoorn); Atrium Medisch Centrum, Heerlen (A.H.C.M.L. Schreuder); Erasmus Medical Center, Rotterdam (A. van der Lugt, P.J. Koudstaal); Flevoziekenhuis, Almere (M. Limburg); Kennemer Gasthuis, Haarlem (M. Weisfelt); Laurentius Ziekenhuis, Roermond (A.G. Korten); Maasstad Ziekenhuis, Rotterdam (R. Saxena); Maastricht University Medical Center (M.E. Kooi, R.J. van Oostenbrugge, W.H. Mess); Orbis Medisch Centrum, Sittard (N.P. van Orshoven); Sint Antonius Ziekenhuis, Nieuwegein (S.C. Tromp); Sint Franciscus Gasthuis, Rotterdam(S.L.M. Bakker); Slotervaartziekenhuis, Amsterdam (N.D. Kruyt); Tergooi Ziekenhuizen, 
Hilversum/Blaricum (J.R. de Kruijk); University Medical Center Utrecht (J. Hendrikse, G.J. de Borst); Viecuri Medisch Centrum, Venlo (B.J. Meems); Vlietland Ziekenhuis, Schiedam (J.C.B. Verhey); IJsselland Ziekenhuis, Capelle a/d IJsel (A.D. Wijnhoud).

\section{References}

1 Chaturvedi S, Bruno A, Feasby T, et al; Therapeutics and Technology Assessment Subcommittee of the American Academy of Neurology. Carotid endarterectomy-an evidence-based review: report of the Therapeutics and Technology Assessment Subcommittee of the American Academy of Neurology. Neurology 2005; 65(06):794-801

2 Rothwell PM, Eliasziw M, Gutnikov SA, et al; Carotid Endarterectomy Trialists' Collaboration. Analysis of pooled data from the randomised controlled trials of endarterectomy for symptomatic carotid stenosis. Lancet 2003;361(9352):107-116

3 Bentzon JF, Otsuka F, Virmani R, Falk E. Mechanisms of plaque formation and rupture. Circ Res 2014;114(12):1852-1866

4 Joshi FR, Lindsay AC, Obaid DR, Falk E, Rudd JH. Non-invasive imaging of atherosclerosis. Eur Heart J Cardiovasc Imaging 2012; 13(03):205-218

5 Kwee RM, van Oostenbrugge RJ, Hofstra L, et al. Identifying vulnerable carotid plaques by noninvasive imaging. Neurology 2008;70(24 Pt 2):2401-2409

6 Saam T, Hatsukami TS, Takaya N, et al. The vulnerable, or highrisk, atherosclerotic plaque: noninvasive MR imaging for characterization and assessment. Radiology 2007;244(01):64-77

7 Yuan C, Mitsumori LM, Beach KW, Maravilla KR. Carotid atherosclerotic plaque: noninvasive MR characterization and identification of vulnerable lesions. Radiology 2001;221(02):285-299

8 Cappendijk VC, Cleutjens KB, Heeneman S, et al. In vivo detection of hemorrhage in human atherosclerotic plaques with magnetic resonance imaging. J Magn Reson Imaging 2004;20(01):105-110

9 Kwee RM, Schreuder FH, Mess WH, et al. Images in cardiovascular medicine: development of carotid intraplaque hemorrhage demonstrated by serial magnetic resonance imaging. Circulation 2009;120(16):1637-1639

10 Takaya N, Yuan C, Chu B, et al. Presence of intraplaque hemorrhage stimulates progression of carotid atherosclerotic plaques: a high-resolution magnetic resonance imaging study. Circulation 2005;111(21):2768-2775

11 Kwee RM, van Oostenbrugge RJ, Mess WH, et al. MRI of carotid atherosclerosis to identify TIA and stroke patients who are at risk of a recurrence. J Magn Reson Imaging 2013;37(05):1189-1194

12 Gupta A, Baradaran H, Schweitzer AD, et al. Carotid plaque MRI and stroke risk: a systematic review and meta-analysis. Stroke 2013;44(11):3071-3077

13 Saam T, Hetterich H, Hoffmann V, et al. Meta-analysis and systematic review of the predictive value of carotid plaque hemorrhage on cerebrovascular events by magnetic resonance imaging. J Am Coll Cardiol 2013;62(12):1081-1091

14 Hosseini AA, Kandiyil N, Macsweeney ST, Altaf N, Auer DP. Carotid plaque hemorrhage on magnetic resonance imaging strongly predicts recurrent ischemia and stroke. Ann Neurol 2013;73(06):774-784

15 Virmani R, Kolodgie FD, Burke AP, Farb A, Schwartz SM. Lessons from sudden coronary death: a comprehensive morphological classification scheme for atherosclerotic lesions. Arterioscler Thromb Vasc Biol 2000;20(05):1262-1275

16 Davies MJ, Thomas A. Thrombosis and acute coronary-artery lesions in sudden cardiac ischemic death. N Engl J Med 1984; 310(18):1137-1140

17 Falk E, Nakano M, Bentzon JF, Finn AV, Virmani R. Update on acute coronary syndromes: the pathologists' view. Eur Heart J 2013;34 (10):719-728
18 Michel JB, Martin-Ventura JL, Nicoletti A, Ho-Tin-Noé B. Pathology of human plaque vulnerability: mechanisms and consequences of intraplaque haemorrhages. Atherosclerosis 2014;234 (02):311-319

19 Duguid JB. The thrombogenic hypothesis and its implications. Postgrad Med J 1960;36:226-229

20 Davies MJ, Thomas AC. Plaque fissuring-the cause of acute myocardial infarction, sudden ischaemic death, and crescendo angina. Br Heart J 1985;53(04):363-373

21 Daemen MJ, Ferguson MS, Gijsen FJ, et al. Carotid plaque fissure: an underestimated source of intraplaque hemorrhage. Atherosclerosis 2016;254:102-108

22 Liem MI, Schreuder FH, van Dijk AC, et al. Use of antiplatelet agents is associated with intraplaque hemorrhage on carotid magnetic resonance imaging: the Plaque at Risk Study. Stroke 2015;46(12):3411-3415

23 Li X, Vink A, Niessen HW, et al. Total burden of intraplaque hemorrhage in coronary arteries relates to the use of coumarintype anticoagulants but not platelet aggregation inhibitors. Virchows Arch 2014;465(06):723-729

24 Lane DA, Philippou H, Huntington JA. Directing thrombin. Blood 2005;106(08):2605-2612

25 Borissoff JI, Spronk HM, Heeneman S, ten Cate H. Is thrombin a key player in the 'coagulation-atherogenesis' maze? Cardiovasc Res 2009;82(03):392-403

26 Hemker HC, Giesen P, Al Dieri R, et al. Calibrated automated thrombin generation measurement in clotting plasma. Pathophysiol Haemost Thromb 2003;33(01):4-15

27 Pingel S, Tiyerili V, Mueller J, Werner N, Nickenig G, Mueller C. Thrombin inhibition by dabigatran attenuates atherosclerosis in ApoE deficient mice. Arch Med Sci 2014;10(01):154-160

28 Preusch MR, Ieronimakis N, Wijelath ES, et al. Dabigatran etexilate retards the initiation and progression of atherosclerotic lesions and inhibits the expression of oncostatin $\mathrm{M}$ in apolipoprotein Edeficient mice. Drug Des Devel Ther 2015;9:5203-5211

29 Bea F, Kreuzer J, Preusch M, et al. Melagatran reduces advanced atherosclerotic lesion size and may promote plaque stability in apolipoprotein E-deficient mice. Arterioscler Thromb Vasc Biol 2006;26(12):2787-2792

30 Kadoglou NP, Moustardas P, Katsimpoulas M, et al. The beneficial effects of a direct thrombin inhibitor, dabigatran etexilate, on the development and stability of atherosclerotic lesions in apolipoprotein E-deficient mice: dabigatran etexilate and atherosclerosis. Cardiovasc Drugs Ther 2012;26(05):367-374

31 Borissoff JI, Otten JJ, Heeneman S, et al. Genetic and pharmacological modifications of thrombin formation in apolipoprotein e-deficient mice determine atherosclerosis severity and atherothrombosis onset in a neutrophil-dependent manner. PLoS One 2013;8(02): e55784

32 Seehaus S, Shahzad K, Kashif M, et al. Hypercoagulability inhibits monocyte transendothelial migration through protease-activated receptor-1-, phospholipase-Cbeta-, phosphoinositide 3-kinase-, and nitric oxide-dependent signaling in monocytes and promotes plaque stability. Circulation 2009;120(09):774-784

33 Carcaillon L, Alhenc-Gelas M, Bejot Y, et al. Increased thrombin generation is associated with acute ischemic stroke but not with coronary heart disease in the elderly: the Three-City cohort study. Arterioscler Thromb Vasc Biol 2011;31(06):1445-1451

34 Loeffen R, Winckers K, Ford I, et al; PROSPER Study Group. Associations between thrombin generation and the risk of cardiovascular disease in elderly patients: results from the PROSPER Study. J Gerontol A Biol Sci Med Sci 2015;70(08):982-988

35 Borissoff JI, Heeneman S, Kilinç E, et al. Early atherosclerosis exhibits an enhanced procoagulant state. Circulation 2010;122 (08):821-830

36 Truijman MTB, Kooi ME, van Dijk AC, et al. Plaque At RISK (PARISK): prospective multicenter study to improve diagnosis of high-risk carotid plaques. Int J Stroke 2014;9(06):747-754 
37 Randomised trial of endarterectomy for recently symptomatic carotid stenosis: final results of the MRC European Carotid Surgery Trial (ECST). Lancet 1998;351(9113):1379-1387

38 Dielis AW, Balliël WM, van Oerle R, et al. Thrombomodulinmodified thrombin generation after in vivo recombinant factor VIII treatment in severe hemophilia A. Haematologica 2008;93 (09):1351-1357

39 Elkind MS, Sacco RL. Stroke risk factors and stroke prevention. Semin Neurol 1998;18(04):429-440

40 Derksen WJ, Peeters W, Tersteeg C, et al. Age and coumarintype anticoagulation are associated with the occurrence of intraplaque hemorrhage, while statins are associated less with intraplaque hemorrhage: a large histopathological study in carotid and femoral plaques. Atherosclerosis 2011;214(01): 139-143

41 Aburahma AF, Robinson P, Decanio R. Prospective clinicopathologic study of carotid intraplague hemorrhage. Am Surg 1989;55 (03):169-173

42 AbuRahma AF, Boland JP, Robinson P, Decanio R. Antiplatelet therapy and carotid plaque hemorrhage and its clinical implications. J Cardiovasc Surg (Torino) 1990;31(01):66-70
43 With Notø AT, Mathiesen EB, Østerud B, Amiral J, Vissac AM, Hansen JB. Increased thrombin generation in persons with echogenic carotid plaques. Thromb Haemost 2008;99(03):602-608

44 Spronk HMH, Dielis AWJH, De Smedt E, et al. Assessment of thrombin generation II: validation of the calibrated automated thrombogram in platelet-poor plasma in a clinical laboratory. Thromb Haemost 2008;100(02):362-364

45 Ten Cate H. Thrombin generation in clinical conditions. Thromb Res 2012;129(03):367-370

$46 \mathrm{Kalz} \mathrm{J}$, ten Cate H, Spronk HM. Thrombin generation and atherosclerosis. J Thromb Thrombolysis 2014;37(01):45-55

47 Ten Cate H, Hemker HC. Thrombin generation and atherothrombosis: what does the evidence indicate? J Am Heart Assoc 2016;5 (08):e003553

48 Páramo JA, Orbe J, Beloqui O, et al. Prothrombin fragment $1+2$ is associated with carotid intima-media thickness in subjects free of clinical cardiovascular disease. Stroke 2004;35(05):1085-1089

49 Altman R, Scazziota A, Herrera L, González C. Relationship between thrombin generation and international normalized ratio in patients receiving oral vitamin $\mathrm{K}$ antagonist therapy. J Thromb Haemost 2007;5(07):1552-1569 